\title{
TRANSNATIONAL THREATS: \\ BLENDING LAW ENFORCEMENT AND MILITARY STRATEGIES
}

\author{
Edited by \\ Carolyn W. Pumphrey
}

November 2000 